\title{
Locating the Internet in the Parks of Havana
}

\author{
Michaelanne Dye \\ Georgia Institute of Technology \\ Atlanta, GA, USA \\ mdye@gatech.edu
}

\author{
Nithya Sambasivan \\ Google Inc.
}

Mountain View, CA, USA

nithyasamba@google.com

\author{
David Nemer \\ University of Kentucky \\ Lexington, KY, USA \\ david.nemer@uky.edu
}

\author{
Amy S. Bruckman \\ Georgia Institute of Technology \\ Atlanta, GA, USA \\ asb@cc.gatech.edu
}

\author{
Laura R. Pina \\ University of Washington \\ Seattle, WA, USA \\ lpina@cs.uw.edu
}

\author{
Neha Kumar \\ Georgia Institute of Technology \\ Atlanta, GA, USA \\ neha.kumar@cc.gatech.edu
}

\begin{abstract}
Since March 2015, the public squares of Havana have been transformed from places where people stroll and children play to places where crowds gather to try to connect to the internet at all hours of the day and night. We present a field investigation of public WiFi hotspots in Havana, Cuba, and examine the possibilities of internet access these limited and expensive hotspots present to individuals, many of who are experiencing the internet for the first time. Drawing on fieldwork conducted in 2015-2016, we underscore the reconfigurations that have resulted from this access, as evolving internet users reconfigure their interactions with place, time, and individuals in their efforts to locate the internet. We also discuss the implications our findings have for the design of internet access interventions in Cuba and in other low-resource environments across the world, as well as the broader implications for social computing across diverse geographies.
\end{abstract}

\section{Author Keywords}

Cuba; internet; WiFi; place; HCI4D; social computing

\section{ACM Classification Keywords}

H.5.m. Information Interfaces and Presentation (e.g. HCI): Miscellaneous

\section{INTRODUCTION}

Around 11.30 PM on a muggy evening in April 2016, Yuniel $^{1}$, a 26 year-old theology student, and his wife, Lara, drive to Habana Vieja. "She needs to fill out an online registration form for school," he says. Neither gets out of the car as Lara pulls out her iPhone and an ETECSA internet card. Shifting glances between the card and the screen, she first enters a long string of numbers for her user name and repeats the process for the password. After waiting about a

\footnotetext{
${ }^{1}$ All names have been changed to protect participants' anonymity.
}

Permission to make digital or hard copies of all or part of this work for personal or classroom use is granted without fee provided that copies are not made or distributed for profit or commercial advantage and that copies bear this notice and the full citation on the first page. Copyrights for components of this work owned by others than ACM must be honored. Abstracting with credit is permitted. To copy otherwise, or republish, to post on servers or to redistribute to lists, requires prior specific permission and/or a fee. Request permissions from permissions@acm.org.

CHI 2017, May 6-11, 2017, Denver, CO, USA.

Copyright is held by the owner/author(s). Publication rights licensed to ACM.

ACM ISBN 978-1-4503-4655-9/17/05 ...\$15.00.

DOI: http://dx.doi.org/10.1145/3025453.3025728 minute, a screen appears with a countdown clock, showing that 58 minutes remain. Lara enters some text and hits send. After another five minutes, the website has still not loaded. "You're wasting our minutes if you keep trying here," Yuniel tells her, "The connection is too slow." Yuniel maneuvers the car through Havana Vieja's crowded streets, past the capitol building, and into the Galeano neighborhood, home of the popular Fe del Valle Park WiFi hotspot. The ten minute drive between hotspots proves useless, however, as large crowds are overloading the router in this park as well. Two hours and four hotspots later, Yuniel and Lara are finally able to dispatch the web form by connecting to the internet from a hotspot near El Malecón. As they start to head home, Yuniel says, "We are very lucky... at least we have a car and don't have to search for the internet on foot."

With nearly four billion people lacking access to the internet [29], efforts to expand internet access are growing rapidly across the world. Cuba remains one of few nations where this access is still affected by historical trade embargoes and restrictions. Since the 2014 announcement of the normalization of relations with the U.S., however, internet access in Cuba is growing. This access is primarily made available through the introduction of approximately 200 public WiFi hotspots in local parks, squares, and streets as of 2016 [18].

Through interviews with 41 participants, participant observation, and fieldwork, our research examines the impact of the newly opened WiFi hotspots in Havana on the lives of local citizens, as they go about their efforts to locate the internet in parks, plazas, and streets. We find that users reconfigure their lives in diverse ways in order to accommodate the model of internet access that these hotspots enable. First, having access to a physical space that is also online has shaped how the local Cuban people interact with this space. There is thus a reconfiguration of 'space' and 'place' that is occurring simultaneously. Second, given the limited and expensive access even in these public settings, users have to carefully prioritize their time while they are online and offline, so that their internet needs are fulfilled affordably. Further, as these Cubans go online to connect with their families after long years of separation, they are finally in a position to try to regain communication with them and reconfigure these relationships. 
By investigating how the rationed, public introduction of the internet impacts lives of users, our paper makes the following contributions. First, our findings document this dynamic process by building on prior research on increasing internet access in Cuba [15]. Second, capturing this transition as it unfolds helps us understand both online and offline constraints and affordances and how these impact internet use and priorities, particularly in the Cuban case. Third, although the specifics of Cuba may materialize differently in other contexts, our study presents design and policy implications for other constrained environments that fall in the purview of the area of Human-Computer Interaction for Development (HCI4D). As services (e.g., Facebook) developed in highlyconnected contexts are increasingly adopted in socioeconomically disadvantaged communities, the nature of access by these new and evolving users must be considered. With this in mind, our paper also provides implications for the social computing community, highlighting the need for it to engage with diversely connected geographies.

Our paper is structured as follows. We begin by briefly describing the sociopolitical context in which our research study took place. After situating our research in a body of related work, we describe the reconfigurations occurring as a result of the nature of internet access in Havana. We then discuss the takeaways of our research for Cuba, the Global South overall, and the social computing research community. The goal of our research is to inform the responsible design of accessoriented interventions for sustainable development. In light of the massive internet access initiatives being undertaken by actors such as Facebook (e.g., Express WiFi [19]) and Google (e.g.,partnership with Indian Railways and RailTel [35]), as well as the growing number of internet users worldwide, our research sheds light on what these efforts might focus on to provide access that holds meaning and value for new and evolving adopters.

\section{BACKGROUND}

In 1996, with the support of the National Science Foundation (NSF), Cuba became one of the first 'developing' countries to connect to the worldwide web. Access was extended to a select few, including certain researchers and government workers, tourists at hotels, and students on college campuses, but not to homes for personal use [37]. As internet use grew rapidly across the Global South, however, access rates in Cuba stagnated. In 2001, Cuba's access to the internet was at its lowest as measured against the "six dimensions of internet access" [54]. With only one state-run telecommunication company that was tightly controlling network access and a single fiber-optic cable that connected Cuba to the world, Cuba was lacking in both technical infrastructure and political will to expand internet access [37]. In addition to the lack of internet access, the ownership of mobile phones was illegal until 2008. This meant that, prior to that date, around 11 million Cubans depended entirely on a limited number of landlines (approx. 900,000) [50] to communicate with an extensive Cuban diaspora. The combination of limited internet access, restrictions on mobile phone ownership, and unreliable postal services has contributed to the effective isolation of Cubans from the rest of the world.
The times are changing, however. The adoption of mobile phones has grown since 2008 and there were more than 2.6 million mobile phone users in 2014 [50]. In addition, in December 2014, the United States and Cuba announced that they would begin the process of normalizing relations $[5,51]$ and, in July 2015, formal diplomatic relations were officially reestablished [11]. The two countries also agreed that Cuba would allow internet access for its people and the U.S. would facilitate this access by permitting Cuba to connect to fiberoptic cables, linking the two countries as well as allowing North American telecommunication companies to do business with Cuba's state-owned enterprises [51]. Research from 2015 showed that Cubans were severely restricted in their internet use [15]. Reports estimated that only 5-25\% of Cubans had access, with only $5 \%$ of the population having full access to the internet (usually through their places of work) [46].

However, the recent introduction of WiFi has changed the nature of internet access for the Cuban people. As of September 2016 , there were 200 hotspots spread across the country, with 28 in the capital city of Havana [18]. These hotspots present ordinary Cubans (regardless of their job or educational status) with the opportunity to connect and communicate across borders. However, as our findings also demonstrate, connecting at these hotspots is not without its challenges. With our study, we seek to provide an enriched understanding of the interconnected triumphs and travails of Cuban WiFi hotspots.

\section{RELATED WORK}

Providing internet access has been a longstanding focus in global development agendas, national policies, and increasingly, the technological industry's growth. We now highlight key research efforts in the areas of public internet provision and constrained networks in the Global South as well as work that considers social computing in these "slow and expensive" contexts. Additionally, we discuss work on WiFi hotspots and reconfiguration in relation to internet access.

\section{Public Access in the Global South}

Since the Millennium Development Goals (MDGs) were drafted in the year 2000 [53], provision of public internet access through state and private entities has proliferated and evolved in 'developing' countries. Shared access computer centers, or telecenters, were one of the earliest and dominant approaches to providing connectivity, from Brazil to India and the Philippines [25, 7, 39]. Modeled as community centers or private businesses, socioeconomic development services were offered on these computers. While a large amount of funding was dedicated to these projects, the telecenter model was by-and-large a failure due to a number of reasons, including financial profitability, insufficient relevant content for user groups, social discrimination, limited digital literacy, and political barriers [7, 52, 4]. Telecenters that managed to become successful diversified, provided auxiliary services, and had motivated champions [38].

Public access continues to be of relevance in 'developing' regions. In a study of South African teenagers, Donner and Walton found that public access in libraries and cybercafes remains important even with mobile data, serving as venues to 
do research, supported by helpful staff [13]. Nemer's ethnography in the favelas of Brazil highlighted the importance of mundane uses of technology in telecenters in the process of social empowerment of slum residents [34]. Notably, Burrell's research on usage of internet cafes by non-elite youth in Accra points to the cafes providing a space to extend one's social network and resources online, an "indeterminate space" that is neither fully Ghanaian nor a totally new world [10]. Miller and Slater, in their ethnography of the internet among Trinidadians, noted that the network became an expression of values and identities of being "naturally Trini," providing a global stage to enact Trini pride, cosmopolitanism, and freedom. The internet served as a window to connect families over long distances [33]. Adding to this work, we point to the outward focus of the internet in the WiFi hotspots, in the re-establishing and re-imagining of diasporic connections between Cuba and the U.S.

\section{Using Slow and Expensive Networks}

Despite the rise of prepaid internet in emerging economies, cost of use remains high. The cost-consciousness of prepaid data users has been noted by Gitau et al. [24] and Mathur et al. [32] in Cape Town, Wyche et al. in Kenya [56], and Sambasivan et al. in India [43], pointing to the barriers and strategies in making use of network infrastructures. Tools to help manage and control data costs have been researched and deployed. Of note is SmartBrowse, a cost transparency tool, that led to increased online activity and a reduction in credit spent [45] and Flywheel, a compression tool for the Chrome browser, that reduces data size of web pages [1]. Our research complements this space by providing an account of how paid WiFi hotspots at slow speeds are optimized by Cubans, when the cost of access is a high fraction of incomes.

As new users find access to the internet, particularly in 'developing' countries, more researchers are examining what these users do online once they get access. In addition to illuminating how and why individuals appropriate social media tools, these studies speak to the worldwide popularity of Social Networking Sites (SNSs), particularly Facebook. Studies in Kenya and India (among others) have examined the perceived affordances and subsequent benefits of Facebook while also examining constraints [56, 31]. Our research contributes to the growing body of work on new internet access and social media use in 'developing' countries [56, 31, 55].

\section{Public WiFi, Reconfiguration, Space and Place}

Public WiFi is increasingly provided by establishments, institutions and governments as a means to boost access in 'developing' countries. Express WiFi by Facebook [19] and Google Station [35] are large-scale deployments in rural and urban areas. However, research on public WiFi use is relatively scarce. Sambasivan and Aoki describe how imaginaries of public WiFi in India are shaped by media and prior technological cultures, leading to specific fears and values [42]. Hampton and Gupta, in their study of WiFi use in U.S. establishments, note that two types of use emerged in the public hotspots: true mobiles, pursuing productive or transactional activities in the hotspots, and place-makers, who viewed the cafes as sociable spaces [27] (see notes on use of cybercafes as "third places" by [41]). Studying community wireless networks in New York City, Forlano describes the impact of the space on use, discussing spatial characteristics that matter in choosing a hotspot and the freedom to move about while using it [21]. As stated by Gaver, the design and physical attributes of space afford actions and behavior in place [23]. However, the widespread adoption of the internet and mobile technology has altered the ways in which we think about the relationship between space and place [14]. Our research connects with prior work on this topic in order to better understand the complexities embedded in our findings.

Drawing on Forlano's work [22], we use the term "reconfigure" to describe the changes that have occurred in the spaces and places of Havana and the lives of participants since the hotspots were introduced. Barad says, "Agency is not an attribute but the ongoing reconfigurings of the world" [6]. Using this notion of agency, we highlight how participants actively and passively reconfigure their interactions in order to access the internet and accomplish their targeted online activities. As Forlano describes, the interactions between people and WiFi networks have reconfigured attributes in physical space, making space a social product just as much as place [22]. Our findings, however, take us beyond the coreconfiguration of space and place by highlighting how factors such as time and social practices play a crucial role in reconfiguration. Our research thus contributes new knowledge to the understanding of public hotspots by examining their use in the context of parks and urban spaces. Specifically, we examine how the nature of access and the characteristics of hotspots influence adoption and use when they serve as the first experience of the internet.

\section{METHODS}

Our data comes from fieldwork conducted in Havana (Cuba) across three phases: December 2015-January 2016, April 2016, and July-August 2016. During this time, we conducted in-depth, semi-structured interviews and participant/nonparticipant observation in multiple WiFi hotspots across Havana. The majority of our observations took place in three hotspots: the plaza of Parque Fe del Valle, Las Rampas, and Parque Central. Our choice of hotspots was based on their popularity among interview participants. We also engaged in non-participant observation in ten other WiFi hotspots located around the city of Havana. Our study was approved by the Institutional Review Boards (IRBs) of the Georgia Institute of Technology and Indiana University.

Our semi-structured interviews were with 41 individuals -24 females and 17 males, ranging in age from 18 to 54, who had experienced WiFi hotspots in Havana. All participants were born, raised, and are living in Cuba. We relied on referrals from contacts made during previous trips to Cuba and used purposeful, snowball sampling to recruit initial participants who referred us to additional contacts [47]. To diversify our participant pool, we interviewed individuals who had connected at WiFi hotspots once to those who tried to connect almost daily. All participants had visited WiFi hotspots previously. We recruited participants until we felt that our data had reached the point of saturation [26]. 
All interviews were conducted in Spanish at a location of the participants' choosing and lasted between 30 to 90 minutes. During the interviews, we asked participants about their experiences at the WiFi hotspots, their motivations for using the internet, the activities they tried to engage in when connected, the perceived impact of use on their daily lives and relationships, and the differences they had experienced in their communities since the introduction of the hotspots. On several occasions, we accompanied participants to WiFi hotspots in order to participate in their process of locating the internet. Due to U.S. laws, we did not compensate participants.

The new policy agreement between the U.S. and Cuba calls for efforts to increase Cubans' access to internet services [51]. All WiFi hotspots we studied have been officially sanctioned by the government. However, to further protect participants, our consent form cautioned individuals to avoid topics they deemed controversial. Our IRB protocol stated that if a subject broached a potentially controversial topic, we would interrupt them and remind them to be careful. Further, in accordance with our IRB protocol, we waived the documentation of consent.

We conducted inductive, iterative, thematic analysis on the interview and observation data collected by Michaelanne, the first author, in April 2016 [9]. After conferring with all authors and discussing emergent themes, she returned for more fieldwork in July 2016. The authors combined the data collected during this trip with the data from David's trip in December 2016 and Michaelanne's trip in April and coded the data again as one unit. All authors discussed the codes and themes throughout this process, bringing diverse combinations of expertise in qualitative methodologies and internet and social media research. Michaelanne is of Cuban descent and has experience conducting qualitative work in Cuba as well as other low-access communities in the U.S. David is an ethnographer who has studied diverse resource-constrained communities in Brazil and Cuba. Laura is an HCI researcher who was born and raised in Cuba and helped to provide additional cultural context when needed. Nithya has years of expertise in driving internet access initiatives in emerging markets at Google. Amy contributes her expertise in studying sociotechnical systems for social computing. Neha is an ethnographer with experience in social media and internet access research in the Global South. The entire team has been engaged through the iterative processes of data collection and analysis.

Cuba and the U.S. have complicated sociopolitical ties and projects such as USAID's Zunzuneo have been designed to undermine the Cuban government within Cuba [2]. Our work aims to steer clear of adopting a particular political stance or suggesting technological interventions that promote a particular political leaning. In the interest of reflexivity, however, we admit that we are all excited to note signs of growing internet access and harbor hopes that this will mean good things for Cuban society. Our research seeks to learn from participants instead of providing a technological intervention intended to "help" them. We do offer implications for design, however, with the intent that they will inform responsible design of future interventions in the area of our work.

\section{FINDINGS}

In 2015, state actors added white, flat, rectangular WiFi routers around the city of Havana, converting squares, parks, and busy streets into hotspots that could help realize the Cuban people's aspirations of connecting to the internet. Due to diverse, enmeshed factors, however, the experience of gaining online access is far more complicated than one might expect. We highlight these complexities below, describing how our participants pursue the internet and highlighting the value they derive in the process. We first introduce the reader to the conditions one must meet for being able to go online. We then describe how the introduction of WiFi routers in public places has led to the reconfiguring of spaces and places, time, and relationships.

\section{Dynamics of Getting Online}

In order to ground our findings related to reconfiguration, we now focus on the arduous process of locating the internet, that starts before one actually enters a hotspot and includes identifying an internet-enabled device, buying internet time, and finding a strong enough connection.

\section{Identifying an Internet-Enabled Device}

Prior to getting online, one must identify an internet-enabled device, such as a smartphone. Though mobile internet is fast becoming popular worldwide [12], and particularly in 'developing' countries, finding a device in Cuba can be prohibitively expensive. One student explained that the cost of a smartphone has made it impossible for her to purchase one:

"The smartphones here are very expensive...I have plans to buy myself one, but they cost a lot of money because they bring them from [the U.S.] and they sell them for a very high price... In reality, I can't acquire one." Dayma $(F, 19)$

Dayma lives next to a hotspot, but her ability to get online depends on how long she can use her sister's tablet. In Cuba, electronic goods are sold at around a 240 percent markup [3]. According to participants, most Cubans purchase their devices from other individuals who have brought them to Cuba from other countries. Even these devices, however, are resold at a 200 percent markup, prohibitively expensive in a country where the median salary is approximately USD 25 per month and variations are low given the political history [16].

Among smartphones, certain devices are viewed as offering a superior internet experience than others. Though they might be more expensive to purchase, they also offer more bang for the buck when it comes to accessing the internet:

"The phone that is better connects faster and costs you less [internet minutes] but there are phones that are of poor quality and they use up more time because there is more of a delay." - Clara (F, 50)

There are tradeoffs in the process of locating the internet, and the citizens must make sense of these before they are able to take advantage of the public hotspots.

\section{Buying Internet Time}

Once an internet-enabled device has been procured, aspiring users must purchase an internet scratch card at one of the ETECSA stores. Scratch cards have unique usernames and 
passwords and are sold at a $2 \mathrm{CUC}^{2}$ per hour rate. Purchasing these cards takes money, time, and patience, since long and slow-moving lines were constantly present outside ETECSA stores. It would normally take $1.5-2$ hours to make it into the store but there was no guarantee that cards would still be available when one's turn came.

Individuals wanting to avoid long lines can purchase cards at WiFi hotspots from tarjeteros, who buy internet cards from ETECSA and resell them for 3 CUC. Users may also purchase an hour of internet time for $1 \mathrm{CUC}$ at Connectify "minihotspots' [3]. Connectify is an application that turns computers into virtual routers. Individuals running Connectify mini-hotspots would connect to the WiFi hotspot with their ETECSA cards and share their internet connection with others there. Connectify is an example of how participants are utilizing external technologies to bypass the prohibitive features of internet access. Although Connectify connections are usually slower, they offer a feasible way to get online.

\section{Hotspot Hopping}

Once participants have procured a device and purchased internet minutes, they must locate themselves at one of Havana's 28 state-sponsored hotspots. Over time, participants have become aware of the best times to visit these places to save time and money, and optimize their internet experience. Participants described "hotspot hopping", that is, visiting multiple hotspots until a suitable connection could be found. Though Yuniel (in the introduction) considered himself lucky because he and Lara were able to drive around to different hotspots to locate a connection, others are not as fortunate. They have learned to adjust their daily routines so they can locate the internet on foot, while optimizing for time, money, and connectivity. Isabella described how her practices have changed as a result of the Fe del Valle park near her house now having WiFi:

"I always walk through the square and connect to see if I can. If it's too slow, I disconnect and I leave... sometimes I go looking for a better spot farther away from my house that has fewer people..."

- Isabella $(F, 39)$

Sara, a journalist, said that connecting to the internet is important for her job. However, the connection at her office is often slower than at the hotspots, which means it takes her longer to finish certain tasks. Many times a week, Sara leaves work with her smartphone and tries to find a hotspot:

"It depends on the time, it depends on how many people you see grouped in that space."-Sara $(F, 27)$

Sara shared that the first thing she checked for in a hotspot was how crowded it was, since this also indicated how slow the connection would be. Sara's description of locating a connection at a hotspot, as well as the knowledge of which spots to try and when, was also the knowledge we developed when trying to get online in Havana. Hotspot hopping is common practice among participants and, along with having to secure a device and purchase internet minutes, contributes to the arduousness of locating the internet.

\footnotetext{
${ }^{2}$ When our fieldwork was conducted, 1 CUC $=$ USD 1.
}

\section{Reconfiguration of Space and Place}

As participants go through the process of locating the internet, a type of reconfiguration is occurring in the spaces and places where connections are offered. We describe how the spaces that house WiFi routers and afford the opportunity to connect are being reconfigured, physically as well as in the minds of participants.

\section{Overcrowding the Space \\ "Before, that park was only a park where you would see kids playing in the afternoon. Now from when you wake up until you go to sleep, all day that park is filled with people. It's never empty." - Dayma $(F, 19)$}

In addition to state actors adding benches and cleaning up trash, one of the most visible changes that has occurred in these spaces is the large influx of people hoping to get online. Since public internet access is only in specific, physical locations, individuals are tethered to these places if they want to get online, which often leads to overcrowding. Although these crowds may wane during early morning hours, according to what we've seen and heard, the WiFi hotspots are never empty, as Yenifer described:

"You see a multitude there, who can hardly talk with family members, because...WiFi is only in specific places... nowhere else." - Yenifer $(F, 40)$

Since the most affordable internet access is geographically limited, internet activity is bound to these locations, which has several consequences. Most obviously, when participants want to connect they are physically tied to one of the few WiFi hotspots around the city. For some individuals who live close to a hotspot, the location of their home has turned into an added convenience. Since Dayma lives around the corner from $\mathrm{Fe}$ del Valle Park, she can sometimes access the internet from her balcony. However, participants who live or work farther away from hotspots connect less frequently than others. Because of the work involved in getting online and the distance she must travel to locate the nearest hotspot, Clara's experience with the internet has been limited.

“Myself, I don't like [the WiFi hotspot] much. One day we tried to connect and we couldn't because there were many people... it made us work to connect so we disconnected." - Clara $(F, 50)$

Clara said she wanted to chat with her sister who lives in Spain but has not tried to connect again because she lives far away from the closest hotspot. The physical location of hotspots, therefore, adds another factor to the work it takes to get online, further complicating the perceptions that participants have of these places.

\section{Reconfiguring Perceptions of Space and Place}

The introduction of WiFi routers and the large crowds they have attracted have changed participants' perceptions of the spaces and places that now house internet signals. Aymee, an English teacher, said that she views the park differently since she and her friends now have a different motivation to visit:

"Now, everything has changed... the place is no longer just a park in our eyes; now it has also become a place to go online." - Aymee (F, 26) 
Because of the introduction of $\mathrm{WiFi}$, these spaces hold new meaning for Aymee; they are now places where she (at times) has the opportunity to connect. However, the introduction of WiFi and the growing crowds it brings has not been met with positive reactions by all. For example, Carmen, a school teacher, said that in her view, the introduction of the internet had compromised the social essence of such spaces:

"The internet is killing the square. People used to talk to each other, look into each other's eyes, but now they only have eyes for their phones." - Carmen $(F, 43)$

Although the reconfiguration of these spaces and places is not always perceived as something positive, connecting to the internet is now understood as the main reason for visiting these places. As a result of this change in perception, new social practices are forming in WiFi hotspots.

\section{Reconfiguring Social Norms in Public Places}

Prior to the introduction of $\mathrm{WiFi}$, it was rare to see people lingering in these parks or plazas after dark. Now, this is considered socially acceptable behavior. Businesses located in hotspots do not ask people to move out of their doorways, front steps, or windowsills. We observed business owners and their clientle stepping around and over people who were trying to use WiFi and were crowding stairs and doorways leading to shops and restaurants. Zamira, a 25 year-old English translator, told us that businesses understand that everyone wants to get online so 'they don't usually get upset with them" for crowding the space. In fact, some restaurants located in hotspots have shifted their seating arrangements to offer better connectivity. For example, during a visit to Las Rampas, we stopped at a restaurant for lunch. The hostess immediately said, "we have a table available by the window! You will get a much better connection there." On further inquiry, the hostess said that she now seats everyone near the window, when possible, because the WiFi signal is stronger there and she assumes that most clientle are eating there so they can also get online.

While it is now seen as socially acceptable to be in WiFi hotspots late into the night and to sit where signals are strongest, the introduction of WiFi has also created tension between new and existing social norms, particularly in relation to privacy. Forlano found that digital and physical spaces regulate behavior in different, sometimes conflicting, ways [22]. For example, her study found conflict and confusion surrounding appropriate behavior when using free WiFi outside of restaurants and cafs without buying food. In our findings, the tensions for participants were more complicated. For example, participants said they often wanted to discuss personal issues with loved ones on IMO, a video-calling application that uses less bandwidth than competing services. However, since WiFi places are often overcrowded, it is difficult (if not impossible) to find a semi-secluded spot that also has a strong-enough signal. Aymee told us that, since she has to go online in a public place, her "privacy is really at risk."

In addition to feeling uncomfortable about having intimate conversations in public, participants also described feeling uncomfortable hearing the conversations of others. Rafael, a 26 year-old artist, added that, because of overcrowding lead- ing to increased noise and slow connection speeds, people "talk really loud" on IMO and "the whole park" hears them. Different levels of intensity and intimacy were observed in these private conversations. Some people connected to their partners to discuss family issues, like Rosa:

"(Juan), I know you are in Panama to provide us with a better life, but you need to be more present in your son's life. He is already 3 and you haven't visited him in 2 years, look at him (pointing phone camera to their son). He has grown so quickly." - Rosa $(F, 32)$

Due to a loss of intimacy from separation, other participants challenged social norms regarding privacy and intimacy to greater degree. Dany, a bartender, was celebrating his fifth wedding anniversary and wanted to surprise his wife, who was in Miami and who he had not seen for five months, with a strip tease in the middle of Parque Central:

"I copied this idea from someone who did the same in Las Rampas. I had this all arranged with my friends, the guy who held the phone while I stripped down is my brother, and the guys who played rhumba in the background are my friends... I know it is a lot of exposure and I might have made some people uncomfortable, including myself and the guys, but I can't do this anywhere else, it has to be here, in a public space... It is all in the name of love." - Dany $(M, 29)$

The strip tease sparked mixed reactions among the people who were present at the park. Some were entertained but others, like Lisa, a college student, did not find it appropriate:

"What a shameless person! He should do this in his own private space...like a hotel room, he can get internet there." - Lisa $(F, 23)$

Dany said he would have liked to strip for his wife in a private place, but he could not afford to pay for a hotel room (and the additional fee for internet access).

\section{Reconfiguration of Time}

In addition to issues of privacy in public places, participants consistently voiced concerns related to issues of time: the time it takes to find a connection, running out of internet time due to slow connection speeds, adjusting the time of their schedules to allot for visits to WiFi hotspots, and planning their online activities prior to connecting to save time. In this section, we describe how participants reconfigure time in an effort to locate the internet in a meaningful way.

\section{Reconfiguring Daily Schedules}

For participants, part of the process of locating the internet involved reconfiguring their personal time. The squares were overcrowded during lunch time and from 5PM to 8PM; visiting these places to connect was almost useless since the routers were overloaded and not accepting new connections. In order to overcome such limitations, participants adjusted their daily schedules and often visited the squares late at night or early in the morning. Some participants, such as Aymee, shifted their work schedules on specific days in order to visit hotspots during work hours to avoid the after-work rush. 
"I think ahead, 'I want to go online today so I have to leave work now. I should leave at 3, not at 5'... the organization of my life and my time management has changed."-Aymee ( F, 26)

On the days she wants to connect, Aymee's time revolves around trying to get online. We learned about several individuals and groups shifting (or reconfiguring) the time of other activities to make time for going online. Participants also reconfigured schedules in response to the crowds wanting to get online (not necessarily to get online themselves). Pedro, a college student, has reconfigured his daily schedule to be able to earn extra money as a street vendor in the evenings at the Fe del Valle hotspot:

"In the day I work as a waiter and at night I come here to make extra cash. I can stay here almost all night long. . . there are people here 24 hours." - Pedro $(M, 19)$

For Pedro, the introduction of $\mathrm{WiFi}$ and the nature of that access has afforded him more opportunities to make money. Street vendors have discovered new business opportunities to sell pizza, guava pastries, and coffee to WiFi users by reconfiguring their schedules to take advantage of late-night crowds. Businesses have also adjusted their hours to accommodate the crowds that now occupy the hotspots late into the night. Some participants expressed frustration, stress, and concern regarding the need to reconfigure their daily schedules to get the best connection. However, those who are earning more as a result were pleased to have this opportunity.

\section{Reconfiguring Time Online}

Due to high costs and slow connection speeds, participants carefully configure/reconfigure how they spend their time online in order to optimize their experience. Claudia, an economist, said that the limited time she has online gives her "fear and anxiety" because of the activities she is unable to accomplish because she "didn't have the time." Claudia shared how she tries to manage her time at hotspots:

\section{"I see that it is slow and I disconnect and leave. I am losing time and money. I leave and then later come back and try it again."-Claudia $(F, 24)$}

Similar to Claudia, Andre, a 31 year-old webmaster, said, "the limitations that we have in this country affect [how I use the internet"]. Due to these limitations, Andre has to be cognizant of how he configures his online time, adding that his "free time online is stressful." In response to constraints, participants have developed strategies to maximize their internet minutes, as Aymee described:

"From the moment I enter the park I start getting online. As I cross the park, I'm online and I'm downloading. I have an app on my phone that downloads Facebook... I download Facebook completely, send and receive messages, photos, everything. I go offline and start reading what I got from Facebook." - Aymee $(F, 26)$

Similar to Aymee, Rafael and Claudia have also found strategies to optimize their online time at hotspots. The couple plans its visits in advance by prioritizing the activities they want to do and dividing them between the two. Rafael equated this practice to sharing meals at a restaurant saying that he and Claudia "each consume different content and then, after we disconnect, we tell each other how it tasted."

Participants viewed time limitations as prohibitive to the diversity of their internet use. The combination of slow speeds, high costs, and fear of spending too much money as a result of both, impacts participants because, as Veronica, a 23 yearold singer, told us, "there is not time to explore." In this way, the nature of internet access in Havana impacts the way that participants are reconfiguring their time online as well as their perceptions of the internet. Participants said that they are limited to the activities they deem primary and are not afforded the time to explore new spaces online.

\section{Reconfiguration of Relationships}

We now focus on how participants are reconfiguring their relationships with Cubans living in the diaspora, their relationships with local Cubans, and their virtual relationships.

\section{Reconfiguring Relationships in Diaspora}

What motivates participants to go through the extensive work required to connect to the internet? As prior work shows [15], participants said they were driven by the desire to re-connect with family members they had long been separated from. Previously, Cuban and U.S. travel restrictions, lack of internet access, cost of phone calls and unreliable airmail practically prohibited communication between participants and members of the large Cuban diaspora abroad. Ana, a 31 year-old computer science professor, told us that hotspots in Havana are packed with people because using the internet to try to reconnect with Cubans in the diaspora "is a necessity" since, previously, Cubans lacked the ability to be able to connect "face-to-face" with those who had immigrated.

Given the number of Cubans who have immigrated out of Cuba [17] and the communication and travel challenges, it is understandable that the potential to reconnect with loved ones motivates internet use. Like Yanet, a 26 year-old marketer, said, "the phenomena of immigration... touches all [Cubans] very deeply." Now that she has the opportunity to reconnect with her friends and family abroad, Yanet said, "Facebook is the only way we stay in touch." All participants agreed that the most important affordance of the WiFi hotspots was the opportunity to reconnect with the Cuban diaspora.

\section{Reconfiguring Local Relationships to Get Online}

Even after users have gained access to the internet, how do they find their way online, especially when time is of the essence and, despite being print literate, many are yet to acquire internet literacy? Smyth et al. have discussed that when new technology adopters have the will, they find a way [48]. Motivated by their "will" to reconfigure distant relationships, participants reconfigured local relationships so others could help them accomplish their goal. Monika, a visual artist, spoke to us the day after she connected at a WiFi hotspot for the first time. Previously, she would occasionally go to hotspots with Alexis, her husband, and have him send messages to her family on her behalf. When we spoke to Monika, she said that she had decided she wanted to learn to connect on her own to talk to her sister in Spain who she had not seen for eight years. 
"So, now, I am going to learn, too, with Alexis who will teach me, because he has seen it more."-Monika $(F, 35)$

When participants were not very familiar with the internet, they would seek help from friends and/or family for navigating it. We found instances of intermediated access discussed in prior HCI research on new technology adopters in resource-constrained settings $[44,36,31]$. As prior work finds [15], accessing the internet is often a collective endeavor. Tasha said she preferred to avoid the work involved in going online. Although she logs in to Facebook every few months, she said, "I'd rather have a friend who knows what they are doing help me keep my account up-to-date." In this way, she has reconfigured her relationship with Veronica and turned her into her "online manager." In fact, while talking with Tasha at a WiFi hotspot, she asked Veronica to update her Facebook profile picture for her. Veronica had already memorized Tasha's Facebook password and said she knew the kind of photo Tasha would want. When asking Tasha if it made her uncomfortable to give Veronica access to her account, Tasha replied:

"I'd rather not have to go through the trouble of connecting myself. Plus, I trust Veronica." - Tasha $(F, 18)$

Tasha said that she and Veronica "have always been close," but giving Veronica access to her Facebook profile involved an additional layer of trust. Since she values, "keeping up her profile," she must rely on Veronica in this way. Other participants spoke about sharing email and LinkedIn logins with friends (in Cuba and abroad). Participants referred to the process of locating the internet as one that is driven by social motivations and achieved through collective means.

\section{Reconfiguring Virtual Relationships}

Due to the nature of access (particularly the constraints), participants spoke about reconfiguring online relationships based on the "virtual" actions of others. For instance, participants are charged differently depending on the size of their emails, however, many did not realize that initially. Yenifer spoke to us about her frustration regarding this discovery:

"When I first got email, I got a photo from a friend in the U.S. It was like 2.5 megas. .. In my attempt to download it (I only had five pesos left on my account) my pesos were used and I couldn't download it. Now... I only open it when it is less than $100 \mathrm{~KB}$. If it has more than that, I leave it there and don't open it." - $\operatorname{Yenifer}(F, 40)$

Yenifer added that there are people with whom she no longer communicates online because they often send her large image files that "eat up" her online minutes. Here we see evidence of how the nature of access limits certain communication while enabling others. For example, Rafael and Claudia said they "have removed friends and acquaintances, on Facebook because these friends posted "inappropriate" items on their timelines. Since they are unable to connect to Facebook regularly, Rafael and Claudia said these posts will stay on their page until they are able to take them down. Rafael added, "It is hard. I can place control on things but I can't control what the other person is posting." On learning that there is a Facebook feature that allows one to review posts before they go online, Rafael said:
"We didn't know that... we have a poor capability of knowing how to use [the internet]... that keeps us from doing a lot of things online." - Rafael $(M, 26)$

Our findings also reveal that privacy concerns affected the frequency with which participants shared information online. Sara told us that her Facebook account was hacked but, since she did not have money to purchase more time, she did not find out about the hack until three weeks later. Since that incident, Sara has become extra careful about security on Facebook by posting less and not interacting with new people as much. These examples demonstrate how the nature of access influences participants to reconfigure not only their online relationships but also the frequency with which they communicate online. As evident in the above examples, the offline factors in Cuba, as well as the design of the online services they can use, led to negative experiences for participants. However, the desire to connect and the aspirational value of the internet motivates most to continue the pursuit of internet in the parks and plazas of Havana.

\section{DISCUSSION}

Our findings highlight the complex process that participants must undertake as they attempt to locate the internet and the reconfigurations that occur along the way. Compared to prior work [15], we found similar relational reconfigurations occurring among participants trying to locate the internet. However, unlike in [15], more people are now able to try to get online in Havana thanks to WiFi hotspots since individuals are no longer limited to places of work or school for internet use. Participants still consider the current nature of access to be prohibitive. In addition to monetary costs, participants found the reconfigurations they must undertake to locate the internet to be problematic. The physical locations of hotspots further complicate the process of getting online, also complicating participants' relationships with these spaces.

Harrison and Dourish consider space the structure of the world; it is where we are located and events happen [28]. Once people start acting and valuing such space, it becomes place. In other words, space is the three-dimensional environment and place is a space with social meanings, norms, conventions, and cultural understandings. The addition of WiFi routers generated new affordances, thereby changing how participants value and act in these spaces. The perceptions of these parks, streets, and squares are being reconfigured since they are no longer "just a park"; they are now places that offer the possibility of connection with those who live outside of Cuba or open up new business opportunities. The nature of access at these new hotspots, simultaneously also creates several tensions as we described. Forlano, in her research on New York's WiFi hotspots, illuminated tensions that arose from digital and physical spaces regulating norms differently [22]. Our findings highlight how these tensions are further complicated when large groups of people are limited to a few public spaces when wanting to connect. As a result of the convergence of two places (public parks and hotspots), the reconfiguration of social norms is not always smooth. For Dany, the WiFi hotspot afforded a way for him to do something intimate for his wife. However, that he was physically bound to a public park meant he had to do his strip tease in 
front of other individuals, many of who were not pleased. The overlap between privacy concerns and the desire to connect with loved ones created tensions between contrasting social norms and expectations.

Participants were also faced with online privacy issues as they tried to go online at these hotspots. They mentioned not having the time to learn about privacy settings, particularly on Facebook. Indeed, social computing researchers have called for privacy policies that are easier to understand [20]. This inability to manage privacy controls meant that participants posted less and un-friended users because they were unsure how to protect their own profiles. While they spoke with a general optimism about the imagined potential of the internet, the current process of locating the internet is strenuous and provides participants with mere droplets of access to accomplish their online goals.

Our paper also extends literature on postcolonial computing by highlighting how Cubans engaged in practices that are culturally located and power-laden. The workarounds to connect the only Cuban submarine cable to the internet in Venezuela, and the effort to locate the internet in Havana assert questions that challenge the global dynamics of power, wealth, and political influence that shape such cultural encounters. Our paper does not aim to solve a problem or make better design for "other" cultures, but we join Irani et al. by bringing a reality that should be central to design practice: "seeing the ways that design is culturally specific should allow us to broaden the conversation about what other practices can count as good design" [30].

In sections that follow, we discuss the implications our findings might have for the future of internet access in Cuba, given the pace at which the Cuban economy is opening itself up to external influence. We also discuss how our findings could inform the design of internet access initiatives in similarly resource-constrained regions that are slowly but steadily working towards including more under- or un-connected individuals and communities to a global and connected network. Finally, we discuss the implications of our findings for researchers and designers in the social computing space.

\section{Implications for Cuba}

Cuba's WiFi hotspots provide our participants with a window into the experience of the full internet, but simultaneously limit that experience due to costs involved. Given that the Cuban government attempts to provide equal access to services such as education and health care [8], it is fair to hope that internet access would follow suit. However, the current droplets of access that seep into hotspots are challenging to acquire and the participants must make the most of them. As more individuals attempt to get online in Cuba, and given current practices of adoption, how might technology and policy be designed to support users in making the most of this limited access? How might existing designs be imported or suitably altered for Cuba to work within constraints, values, and legal boundaries? These are questions our research raises.

One example of an external service that has helped participants negotiate boundaries is Connectify. While not designed for Cuba specifically, it directly contributes to bringing more
Cubans online by allowing connections to be shared. Further, upon hearing about the popularity of Connectify in Cuba, the company started the Viva Hotspot campaign, which allowed Cuban citizens to use premium features for free [49]. We see potential for other services to leverage this type of model to support internet access for more individuals in the country.

In addition to technical services, the spaces and places from which users access the internet also impact online experience. How might we better consider the spaces where individuals access the internet? One example comes from two Cuban designers who recently unveiled plans for a "modular system of urban furniture" for WiFi hotspots [40]. The design, which has already received interest from the Cuban government, maximizes space while also providing more privacy, seating, shade and solar-powered charging stations. If incorporated into more hotspots, this creative solution could assist participants in providing a friendlier user experience.

We hope for further research like ours to examine local practices so as to see how existing technology might more suitably map to local contexts. However, researchers, companies, and others hoping to engage with Cuba need to consider the delicate, complicated area they are entering. For example, by studying more specifically how individuals negotiate the boundaries of legality in Cuba, external actors might be able to inform the design of services that are more effective in providing a meaningful, non-controversial, online experience.

\section{Implications for the Global South}

Cubans are by no means the only ones to have limited access to the internet. Millions worldwide, especially in the Global South, experience constrained internet access due to infrastructural and cost limitations [12, 32, 45]. Although the specifics of Cuba such as public hotspots, high literacy, proximity to a large western economy, may materialize differently in other contexts, several of these facets may apply in isolation to other cases as well.

First, Cubans going online help us understand how a closed society opens up, and the resultant value shifts, appropriations, and relevant uses for the internet. How do less open societies experience the internet when (some) barriers are removed? What are the longer term implications on expression and becoming more fully participating members online? One might hope to see the emergence of a virtual public sphere. However, our findings show that although participants expressed a desire to more fully explore the "imagined" potential of the internet [55], current barriers limited online participation to the basics. In future work, we plan to track whether more diverse uses emerge in Cuba as internet access likely increases and study the implications this has for other tightly controlled geopolitical environments.

Second, even when access points increased in Cuba, the experience of the internet was still limited by slow speeds and high costs of sessions. Such constraints mirror the conditions in several emerging economies. Our findings point to how creative workarounds developed when connectivity was premium. For example, Rafael and Claudia divided up their activities among each other and Aymee downloaded Facebook content through an application. Constrained access environ- 
ments like Cuba's call for software developers to build applications and services that perform seamlessly on slow networks and are respectful of bandwidth. When every byte has impact on an individual's monetary balance, software design should be mindful of upstream and downstream data. Tools like Facebook Lite ${ }^{3}$, Opera Mini ${ }^{4}$, and Flywheel on Chrome ${ }^{5}$ are steps in the right direction for such constrained networks. Designers could also consider how applications and services can behave when connectivity is not ever-present. Caching and store-and-forward techniques can help individuals make use of software when offline and effectively stretch their experience of the internet.

\section{Implications for Social Computing}

Our findings present relevant takeaways for those working in the social computing space. SNSs are frequently designed with the assumption of constant connectivity. As more users try to access SNSs in constrained settings, designers and researchers might consider how social computing services could be leveraged to support constraints and situated online interactions (e.g., when access is limited to parks). As services like Facebook that have been developed in highly-connected contexts are increasingly adopted in resource-constrained communities, the nature of access by these new and evolving users must be considered. We offer Cuba as a case study to provide details of how a society that functions on extreme connectivity constraints attempts to navigate social computing technologies.

How do the various spaces and places from which users access these online communities impact their experiences? In the case of Cuba, participants are physically bound to public spaces when trying to use services like Facebook and IMO and this impacts the nature of their use. Further, our findings reveal the necessity of local workarounds and services like Connectify in order for participants to get online and to use services like Facebook. In the case of Aymee, she uses a separate application to download content from Facebook for offline viewing. By studying how these services are used and appropriated in specific contexts, social computing researchers and designers may be able to inform the design of more responsible designs of SNSs.

When internet access is constrained, privacy considerations for social computing technologies must also expand. Our findings show that privacy concerns motivated participants' reconfigurations with each category: space and place, time, and relationships. A clearer, more accessible explanation of privacy settings on Facebook and other social media sites would assist in saving time and money while also helping to create a more engaging online experience. For example, participants could be given the option of receiving a text-based email explanation of privacy settings. This email should contain cost-saving strategies directly related to Facebook use in resource-constrained settings and should also be written in the local language.

\footnotetext{
${ }^{3} \mathrm{https}: / / \mathrm{www}$. facebook.com/lite/

${ }^{4}$ http://www.opera.com/mobile/mini

${ }^{5}$ https://goo.gl/crFQmr
}

In addition to privacy concerns, our findings show how participants reconfigured their local relationships through intermediated technology use. Specifically, individuals shared their Facebook, LinkedIn, and email passwords with others to negotiate time, money, and experience constraints. For example, Tasha relied on her friend Veronica to update Tasha's Facebook profile on a regular basis since Veronica was able to get online more frequently. In order to better support such practices, it would be helpful to have a feature on these and other similar services that allows users the option to assign others as "managers" for individual accounts (similar to the option that now exists for managers of Facebook pages). Such a feature would facilitate more control over profiles by allowing individuals to choose the aspects of their profiles others can edit and have access to while still being able to leverage the collective strategies of internet access that have developed in Cuba, as well as other parts of the world where intermediated access occurs frequently [44]. While these implications have been lifted from context-specific findings, we feel that they are relevant for many other communities outside of Cuba. As more and more users get online, both in under- and highly-connected communities, it is critical that we consider the impacts of various technologies, the reconfigurations occurring at multiple levels, and how, as designers, we can support more desirable reconfigurations for and among users.

\section{CONCLUSION}

We presented a qualitative study of public WiFi hotspots in Havana, Cuba, and described how these facilitate internet access for individuals, many of who are experiencing the internet for the first time. Through fieldwork consisting of interviews and observations, we examined the way in which Cubans are integrating the internet into their daily lives at these WiFi hotspots. In particular, we underlined the reconfigurations that have resulted from this access, as new and evolving internet users reconfigure their interactions with space and place, time, and relationships in an effort to locate the internet. We also discussed the implications our findings have for the design of internet access interventions in Cuba and other low-resource environments across the world as well as for social computing more generally. By investigating the rationed introduction of public internet access in Havana, our paper highlights both online and offline constraints and affordances and how these impact internet use, priorities, and daily living.

\section{ACKNOWLEDGMENTS}

We are grateful to our participants for being involved in this research. We also thank anonymous reviewers for their valuable feedback. This work is supported by NSF IIS-1552364.

\section{REFERENCES}

1. Victor Agababov, Michael Buettner, Victor Chudnovsky, Mark Cogan, Ben Greenstein, Shane McDaniel, Michael Piatek, Colin Scott, Matt Welsh, and Bolian Yin. 2015. Flywheel: Googles data compression proxy for the mobile web. In NSDI. 367-380.

2. Alberto Arce, Desmond Butler, and Jack Gillum. 2014. US secretly created 'Cuban Twitter' to stir unrest. (2014). https://goo.gl/glneEt 
3. Ed Augustin. 2016. Connectify, zapya, Revolico: Cubans are using simple hacks and apps to get around limited and expensive internet. Quartz (2016). https : //g00.gl/y8PgP 6

4. Savita Bailur. 2006. Using stakeholder theory to analyze telecenter projects. ITID 3, 3 (2006), pp-61.

5. Peter Baker. 2014. U.S. to Restore Full Relations With Cuba, Erasing a Last Trace of Cold War Hostility. (12 2014). https ://goo.gl/1m2nNP

6. Karen Barad. 2003. Posthumanist Performativity: Toward an Understanding of How Matter Comes to Matter. Journal of Women in Culture and Society 28, 3 (2003), 801-831.

7. Michael L Best and Rajendra Kumar. 2008. Sustainability failures of rural telecenters: Challenges from the sustainable access in rural india (sari) project. ITID 4, 4 (2008), 31-45.

8. Ellery Roberts Biddle. 2013. Rationing the Digital: The Politics and Policy of Internet Use in Cuba Today. Internet Monitor Special Report Series 1 (7 2013). DOI : http://dx.doi.org/10.2139/ssrn. 2291721

9. Virginia Braun and Victoria Clarke. 2006. Using Thematic Analysis in Psychology. Qualitative Research in Psychology (2006).

10. Jenna Burrell. 2012. Invisible users: Youth in the Internet cafés of urban Ghana. Mit Press.

11. Karen DeYoung. 2015. U.S. and Cuba set to formally reestablish diplomatic relations - The Washington Post. (7 2015). https : //goo.gl/pFl3ty

12. Jonathan Donner. 2015. After Access: Inclusion, Development, and a More Mobile Internet. MIT Press.

13. Jonathan Donner and Marion Walton. 2013. Your phone has internet-why are you at a library PC? Re-imagining public access in the mobile internet era. In IFIP Conference on Human-Computer Interaction. Springer, 347-364.

14. Paul Dourish. 2006. Re-space-ing Place: "Place" and "Space" Ten Years on. In CSCW. 299-308.

15. Michaelanne Dye, Annie Antón, and Amy S Bruckman. 2016. Early Adopters of the Internet and Social Media in Cuba. CSCW (2016).

16. Empleo y Salarios 2015. https ://goo.gl/Vqfnoc

17. Sharon R. Ennis, Merarys Rios-Vargas, and Nora G. Albert. 2011. The Hispanic Population: 2010. (2011).

18. ETECSA. 2015. Espacios públicos de conexión inalámbrica (WIFI). (2015). http://www.etecsa.cu/internet

19. Facebook Strives to Bring Cheap Wi-Fi to Rural India 2015. http: //goo.gl/j6wKPa

20. C Fiesler, JL Feuston, and AS Bruckman. 2015. Understanding Copyright Law in Online Creative Communities. CSCW (2015).
21. Laura Forlano. 2008. Anytime? anywhere?: Reframing debates around community and municipal wireless networking. The Journal of Community Informatics 4, 1 (2008).

22. Laura Forlano. 2009. WiFi Geographies: When Code Meets Place. The Information Society 25, 5 (2009), 344-352. DOI : http://dx.doi.org/10.1080/01972240903213076

23. William W. Gaver. 1992. The Affordances of Media Spaces for Collaboration. In CSCW. 17-24.

24. Shikoh Gitau, Gary Marsden, and Jonathan Donner. 2010. After access: challenges facing mobile-only internet users in the developing world. In CHI. ACM, 2603-2606.

25. Ricardo Gomez. 2014. When you do not have a computer: Public-access computing in developing countries. ICTD 20, 3 (2014), 274-291.

26. Greg Guest, Arwen Bunce, and Laura Johnson. 2006. How many interviews are enough? An experiment with data saturation and variability. Field methods 18, 1 (2006), 59-82.

27. Keith N Hampton and Neeti Gupta. 2008. Community and social interaction in the wireless city: wi-fi use in public and semi-public spaces. New Media \& Society 10, 6 (2008), 831-850.

28. Steve Harrison and Paul Dourish. 1996. Re-place-ing Space: The Roles of Place and Space in Collaborative Systems. In CSCW. 67-76.

29. Internet World Penetration Rates 2016. http://www. internetworldstats. com

30. Lilly Irani, Janet Vertesi, Paul Dourish, Kavita Philip, and Rebecca E Grinter. 2010. Postcolonial computing: a lens on design and development. In CHI. ACM, 1311-1320.

31. Neha Kumar. 2014. Facebook for self-empowerment? A study of Facebook adoption in urban India. New Media \& Society 16, 7 (2014), 1-16.

32. Arunesh Mathur, Brent Schlotfeldt, and Marshini Chetty. 2015. A mixed-methods study of mobile users' data usage practices in South Africa. In International Joint Conference on Pervasive and Ubiquitous Computing. ACM, 1209-1220.

33. Daniel Miller and Don Slater. 1995. The Internet: An Ethnographic Approach. Berg Publishers.

34. David Nemer. 2016. Online Favela: The Use of Social Media by the Marginalized in Brazil. Information Technology For Development 22, 3 (2016), 364-379.

35. Official Google Blog: Bringing the Internet to more Indiansstarting with 10 million rail passengers a day 2015. 
36. Tapan S. Parikh and Edward D. Lazowska. 2006. Designing an architecture for delivering mobile information services to the rural developing world. In $W W W$. ACM Press, 791-800.

37. Larry Press. 2011. Past, Present, and Future of the Internet in Cuba. Association for the Study of the Cuban Economy 21 (2011).

38. Nimmi Rangaswamy. 2008. Telecenters and Internet cafés: the case of ICTs in small businesses. Asian Journal of Communication 18, 4 (2008), 365-378.

39. Katherine Reilly and Ricardo Gómez. 2001. Comparing approaches: telecentre evaluation experiences in Asia and Latin America. EJISDC 4 (2001).

40. Monica Rivera. 2016. Parawifi: Conectarse y estar comodo. OnCuba (September 2016). https://goo.gl/TcbZX2

41. Tony Salvador, John W Sherry, and Alvaro E Urrutia. 2005. Less cyber, more café. ICTD 11, 1 (2005), 77-95.

42. N Sambasivan and P. M. Aoki. 2017. Imagined Connectivities: Synthesized Conceptions of Public Wi-Fi in Urban India. In $C H I$.

43. Nithya Sambasivan, Gulzar Azad, Paul M Aoki, and Saswati Saha Mitra. 2016. "We call it Hi-Fi": Exposing Indian Households to High Speed Broadband Wireless Internet. In ICTD.

44. Nithya Sambasivan, Ed Cutrell, Kentaro Toyama, and Bonnie Nardi. 2010. Intermediated technology use in developing communities. In CHI. ACM Press, New York, New York, USA, 2583.

45. Nithya Sambasivan, Paul Lee, Greg Hecht, Paul M Aoki, Maria-Ines Carrera, Jenny Chen, David Pablo Cohn, Pete Kruskall, Everett Wetchler, Michael Youssefmir, and others. 2013. Chale, how much it cost to browse?: results from a mobile data price transparency trial in Ghana. In ICTD. ACM, 13-23.
46. Nancy Scola. 2014. Only 5 percent of Cubans can get on the same Internet Americans do. That could soon change. (2014). https://goo.gl/x1Pxye

47. Irving Seidman. 2012. Interviewing as qualitative research: A guide for researchers in education and the social sciences. Teachers College Press, New York, NY. https://books.google.com/books?hl=en

48. Thomas N. Smyth, John Etherton, and Michael L. Best. 2010. MOSES. In CHI. ACM Press, New York, New York, USA, 1059.

49. Isabella T. 2016. Use Connectify Hotspot to Share Internet Access in Cuba. https://goo.gl/a0Rl7e. (Aug 2016).

50. Tecnologia de la Informacion y Las Comunicaciones 2015. https ://goo.gl/DwQ9cj

51. The White House. 2014. FACT SHEET: Charting a New Course on Cuba. (2014). https : //goo.gl/NVPnkp

52. Kentaro Toyama and Renee Kuriyan. 2007. Review of research on rural PC kiosks. Microsoft Research India (2007).

53. United Nations Millennium Development Goals 2015. http://www.un.org/millenniumgoals/

54. Peter Wolcott, Larry Press, William McHenry, Seymour Goodman, and William Foster. 2001. A Framework for Assessing the Global Diffusion of the Internet. Journal of the Association for Information Systems 2, 6 (2001), $1-50$.

55. Susan Wyche and Eric P. S. Baumer. 2016. Imagined Facebook: An exploratory study of non-users' perceptions of social media in rural Zambia. New Media and Society (2016), 1-17.

56. Susan P Wyche, Sarita Yardi Schoenebeck, and Andrea Forte. 2013. Facebook is a luxury: An exploratory study of social media use in rural Kenya. In $C S C W$. ACM, $33-44$. 